\title{
Genetically modified crops safety assessments: present limits and possible improvements
}

\author{
Gilles-Eric Séralini ${ }^{1 *}$, Robin Mesnage ${ }^{1}$, Emilie Clair ${ }^{1}$, Steeve Gress ${ }^{1}$, Joël Spiroux de Vendômois², Dominique Cellier ${ }^{3}$
}

\begin{abstract}
Purpose: We reviewed 19 studies of mammals fed with commercialized genetically modified soybean and maize which represent, per trait and plant, more than $80 \%$ of all environmental genetically modified organisms (GMOs) cultivated on a large scale, after they were modified to tolerate or produce a pesticide. We have also obtained the raw data of 90-day-long rat tests following court actions or official requests. The data obtained include biochemical blood and urine parameters of mammals eating GMOs with numerous organ weights and histopathology findings.

Methods: We have thoroughly reviewed these tests from a statistical and a biological point of view. Some of these tests used controversial protocols which are discussed and statistically significant results that were considered as not being biologically meaningful by regulatory authorities, thus raising the question of their interpretations.

Results: Several convergent data appear to indicate liver and kidney problems as end points of GMO diet effects in the above-mentioned experiments. This was confirmed by our meta-analysis of all the in vivo studies published, which revealed that the kidneys were particularly affected, concentrating $43.5 \%$ of all disrupted parameters in males, whereas the liver was more specifically disrupted in females (30.8\% of all disrupted parameters).

Conclusions: The 90-day-long tests are insufficient to evaluate chronic toxicity, and the signs highlighted in the kidneys and livers could be the onset of chronic diseases. However, no minimal length for the tests is yet obligatory for any of the GMOs cultivated on a large scale, and this is socially unacceptable in terms of consumer health protection. We are suggesting that the studies should be improved and prolonged, as well as being made compulsory, and that the sexual hormones should be assessed too, and moreover, reproductive and multigenerational studies ought to be conducted too.
\end{abstract}

\section{Background, aim, and scope}

Recently, an ongoing debate on international regulation has been taking place on the capacity to predict and avoid adverse effects on health and the environment for new products and novel food/feed (GMOs, chemicals, pesticides, nanoparticles, etc.). The health risk assessments are often, but not always, based on the study of blood analyses of mammals eating these products in subchronic tests, and more rarely in chronic tests. In particular, in the case of GMOs, the number and nature of parameters assessed, the length of the necessary tests, the statistics used and their interpretations are the subject of controversies, especially in the application of Organization of Economic Cooperation and Development (OECD)

\footnotetext{
* Correspondence: criigen@unicaen.fr

'Laboratory of Biochemistry - IBFA, University of Caen, Esplanade de la Paix, 14032 Caen, Cedex, France

Full list of author information is available at the end of the article
}

norms. Confusion is perceived even in regulatory agencies, as in the European Food Safety Authority (EFSA) GMO panel working group and its guidelines. Doubt has arisen on the role and necessity of animal feeding trials in safety and nutritional assessments of GM plants and derived food and feed [1]. Based on the literature data, EFSA first admitted (p. S33) that for other tests than GMOs: "For 70\% (57 of 81) of the studies evaluated, all toxicological findings in the 2-year tests were seen in or predicted by the 3-month subchronic tests". Moreover, they also indicated (p. S60) that "to detect effects on reproduction or development [...] testing of the whole food and feed beyond a 90-day rodent feeding study may be needed." We fully agree with these assumptions. This is why we think that in order to protect large populations from unintended effects of novel food or feed, imported or cultivated crops on a large scale, chronic 2-year and reproductive and developmental tests are crucial.

\section{SpringerOpen ${ }^{\circ}$}


However, they have never been requested by EFSA for commercial edible crops. We therefore wish to underline that in contrast with the statements of EFSA, all commercialized GMOs have indeed been released without such tests being carried out, and as it was the case recently with maize stacked events without 90-day in vivo mammalian tests being conducted. GM stacked events have the cumulated characteristics of first generation of GMOs (herbicide tolerance and insecticide production), which are mostly obtained by hybridization. For instance, Smarstax maize contains two genes for herbicide tolerance and six genes for insecticide production. In fact, this contradictory possibility was already highlighted in the same review by EFSA (p. S60), when substantial equivalence studies and other analyses were performed: "animal feeding trials with rodents [...] adds little if anything [...], and is not recommended." This is why, in this work we will analyze and review deficiencies in GMO safety assessments, not only performed by biotech companies, but also by regulatory agencies.

We will focus on the results of available 90-day feeding trials (or more) with commercialized GMOs, in the light of modern scientific knowledge. We also suggest here an alternative to conventional feeding trials, to understand the biological significance of statistical differences. This approach will make it possible to avoid both false negative and false positive results in order to improve safety assessments of agricultural GMOs before their commercialization for cultivation and food/feed use and imports.

\section{Overview of the safety studies of GMOs performed on mammals}

Our experience in scientific committees for the assessment of environmental and health risks of GMOs and in biological, biostatistical research, and medicine, as well as in the research relative to side effects [2-6] allowed us to review and criticize mammalian feeding trials with GMOs and make new proposals. Mammalian feeding trials have been usually but not always performed for regulatory purposes in order to obtain authorizations or commercialization for GM plantderived foods or feed. They may have been published in the scientific literature afterwards; however, without public access to the raw data.

We have obtained, following court actions or official requests, the raw data of several 28- or 90-day-long safety tests carried out on rats. The thing we did was to thoroughly review the longest tests from both a biostatistical and a biological point of view. Such studies often analyze the biochemical blood and urine parameters of mammals eating GMOs, together with numerous organ weights and histopathology. We have focused our review on commercialized GMOs which have been cultivated in significant amounts throughout the world since 1994 (Table 1). We observe and emphasize that all the events in Table 1 correspond to soybean and maize which constitute $83 \%$ of the commercialized GMOs, whilst other GMOs not displayed in the table, but still commercialized, are canola or cotton. However, they are not usually directly consumed [7]. Only Sakamoto's and Malatesta's studies have been more than 90 days long (104 weeks and 240 days with blood analyses in Japanese for the first one). Moreover, such tests are not obligatory yet for all GMOs. No detailed blood analysis is available for Malatesta's study, as it mostly includes histochemistry at the ultrastructural level; moreover, the latter tests have not been used to obtain the commercial release by the firm. However, this work has been performed by researchers independent from the GMO industry; it is an important element to take into account for an objective interpretation of the facts, as pointed out in the case of the risk assessments conducted by regulatory agencies with Bisphenol A. For instance in the latter case, it was observed that none of the industry-funded studies showed adverse effects of Bisphenol A, whereas 90\% of government-funded studies showed hazards at various levels and various doses [8]. However, regulatory agencies still continue to refer only to industry-funded studies because they are supposed to follow OECD norms, even if such standards are not always appropriate for the detection of environmental hazards [9]. In this paper, Myers et al. showed that hundreds of laboratory animals and cell culture studies were rejected by regulatory authorities because they did not follow the Good Laboratory Practices (GLP). The Food and Drug Administration and EFSA have based their final decision on two industry-funded studies, claiming that they were superior to the others because they followed GLP. Yet, GLP are based on ancient paradigms. They have serious conceptual and methodological flaws, and do not take into account the latest knowledge in environmental sciences. For example, in the case of Bisphenol A assessment, the animal models used are known to be insensitive to estrogen (CD-1 mouse). Also, assays and protocols in some OECD guidelines are out of date and insensitive. It is obvious that new product assessments should be based on adapted studies using state-of-the-art experiments. The significant gap between scientific knowledge and regulations should be filled also in the case of GMOs [9]. Therefore, some tests presented here show controversial results or statistically significant results that were not considered as biologically significant by EFSA, raising the question of their interpretation.

First of all, the data indicating no biological significance of statistical effects in comparison to controls have been published mostly by companies from 2004 onwards, and at least 10 years after these GMOs were 
Table 1 Review of the longest chronic or subchronic toxicity studies in mammals fed with commercialized GM soybean and maize representing more than $80 \%$ of edible GMOs (2010)

\begin{tabular}{|c|c|c|c|c|c|c|}
\hline References & Plant & Pesticide contained & $\begin{array}{c}\text { Name of } \\
\text { event }\end{array}$ & Species & Duration & Main observations \\
\hline$[17,38,39,19,15]$ & Soybean & Roundup herbicide & mCP4 EPSPS & Mouse & 240 days & $\begin{array}{l}\text { Ultrastructural histochemistry } \\
\text { disturbed }\end{array}$ \\
\hline [14] & Soybean & Roundup herbicide & mCP4 EPSPS & Rat & 91 days & Weight problems \\
\hline$[40]$ & Soybean & Roundup herbicide & $\begin{array}{l}\text { Optimum GAT } \\
\text { DP-356Ø43-5 }\end{array}$ & Rat & 93 days & Statistical differences ${ }^{a}$ \\
\hline$[41]$ & Soybean & Roundup herbicide & Not precise & Rat & 104 weeks & Statistical differences ${ }^{a}$ \\
\hline [42] & Maize & Roundup herbicide & $\begin{array}{l}\text { Optimum GAT } \\
\text { DP- } \varnothing 9814 \varnothing-6\end{array}$ & Rat & 91 days & Statistical differences ${ }^{a}$ \\
\hline$[43,5]$ & Maize & Roundup herbicide & NK603 & Rat & 90 days & Controversial results \\
\hline$[44,5]$ & Maize & mCry1Ab insecticide & MON810 & Rat & 90 days & Controversial results \\
\hline$[25,2,4,5]$ & Maize & mCry3Bb1 insecticide & MON863 & Rat & 90 days & Controversial results \\
\hline [16] & Maize & mBt insecticide & not indicated & Rat & $\begin{array}{l}\text { Multi- } \\
\text { generational } \\
(\mathrm{F} 3)\end{array}$ & $\begin{array}{c}\text { Histopathological, } \\
\text { biochemical, organ weights } \\
\text { alterations }\end{array}$ \\
\hline [45] & Maize & $\begin{array}{l}\text { mCry } 1 F \text { insecticide - glufosinate ammonium- } \\
\text { based herbicide }\end{array}$ & DAS- $\varnothing 15 \varnothing 7-1$ & Rat & 91 days & Statistical differences ${ }^{a}$ \\
\hline$[46,47]$ & Maize & $\begin{array}{l}\text { mCry34Ab1, mCry35Ab1 insecticides - } \\
\text { glufosinate ammonium-based herbicide }\end{array}$ & DAS-59122-7 & Rat & 90 days & Statistical differences ${ }^{a}$ \\
\hline$[48]$ & Maize & $\begin{array}{l}\text { mCry1F, mCry34Ab1, mCry35Ab1 insecticides } \\
\text { - glufosinate ammonium-based herbicide }\end{array}$ & $\begin{array}{l}\text { DAS- } \varnothing 15 \varnothing 7-1 \\
\times \text { DAS-59122-7 }\end{array}$ & Rat & 92 days & Statistical differences ${ }^{a}$ \\
\hline
\end{tabular}

${ }^{a}$ Statistical differences are not biologically meaningful for the authors; however, this can be debated. Oilseed rape and cotton have been excluded because they are not directly edible and not primarily grown for feed. This table includes authorized events for food and feed at least in the European Union and America.

first commercialized round the world. This is a matter of grave concern. Moreover, only three events were tested for more than 90-days in feeding experiments or on more than one generation. This method was not performed by industries which conducted 90-day tests (with blood and organ analyses), but it was in some cases only. However, a 90-day period is considered as insufficient to evaluate chronic toxicity [1,5]. All these commercialized cultivated GMOs have been modified to contain pesticides, either through herbicide tolerance or by producing insecticides, or both, and could therefore be considered as "pesticide plants." Almost all GMOs only encode these two traits despite claims of numerous other traits. For instance, Roundup ready crops have been modified in order to become insensitive to glyphosate. This chemical together with adjuvants in formulations constitutes a potent herbicide. It has been used for many years as a weed killer by blocking aromatic amino acid synthesis by inhibition of 5-enolpyruvylshikimate-3phosphate synthase (EPSPS). Most Roundup ready plants have been modified thanks to the insertion of a mutated EPSPS gene coding for a mutated enzyme, which is not inhibited by glyphosate. Therefore, GM plants exposed to glyphosate-based herbicides such as Roundup do not specifically degrade glyphosate. They can even accumulate Roundup residues throughout their life, even if they excrete most of such residues. Glyphosate and its main metabolite AMPA (with its own toxicity) are found in GMOs on a regular and regulatory basis $[10,11]$. Therefore, such residues are absorbed by people eating most GM plants (as around $80 \%$ of these plants are Roundup tolerant). On the other hand, about $20 \%$ of the other GMOs do synthesize new insecticide proteins through the insertion of mutated genes derived from Bacillus thuringiensis (Bt).

Usually, pesticides are tested over a period of 2 years on a mammal, and this quite often highlights side effects. Additionally, unintended effects of the genetic modification itself cannot be excluded, as direct or indirect consequences of insertional mutagenesis, creating possible unintended metabolic effects. For instance, in the MON810 maize, the insertion of the transgene in the ubiquitine ligase gene caused a complex recombination event, leading to the synthesis of new RNA products encoding unknown proteins [12]. Thus, genetic modifications can induce global changes in the genomic, transcriptomic, proteomic, or metabolomic profiles of the host. The frequency of such events in comparison to classical hybridization is by nature unpredictable. In addition, in a plant producing a Cry $1 \mathrm{Ab}$-modified toxin, a metabolomic study [13] revealed that the transgene introduced indirectly $50 \%$ changes in osmolytes and branched amino acids.

\section{Review of statistical effects after GMO consumption}

Some GMOs (Roundup tolerant and MON863) affect the body weight increase at least in one sex [2,14]. It is a parameter considered as a very good predictor of side 
effects in various organs. Several convergent factors appear to indicate liver and kidney problems as end points of GMO diet effects in these experiments $[2,5,15,16]$. This was confirmed by our meta-analysis of all in vivo studies published on this particular topic (Table 2). The kidneys are particularly affected, concentrating $42 \%$ of all parameters disrupted in males. However, other organs may be affected too, such as the heart and spleen, or blood cells [5].

\section{Liver parameters}

For one of the longest independent tests performed, a GM herbicide-tolerant soybean available on the market was used to feed mice. It caused the development of irregular hepatocyte nuclei, more nuclear pores, numerous small fibrillar centers, and abundant dense fibrillar components, indicating increased metabolic rates [17]. It was hypothesized that the herbicide residues could be responsible for that because this particular GM plant can absorb the chemicals to which it was rendered tolerant. Such chemicals may be involved in the abovementioned pathological features. This became even clearer when Roundup residues provoked similar features in rat hepatic cells directly in vitro [18]. The reversibility observed in some instances for these parameters in vivo [19] might be explained by the heterogeneity of the herbicide residues in the feed [20]. Anyway, these are specific parameters of ultrastructural dysfunction, and the relevance is clear. The liver is reacting. The Roundup residues have been also shown to be toxic for human placental, embryonic, and umbilical cord cells [21-23]. This was also the case for hepatic human cell lines in a comparable manner, inducing nuclei and membrane changes, apoptosis and necrosis [24].

The other major GMO trait has to do with the mutated $(\mathrm{mBt})$ insecticidal peptidic toxins produced by transgenes in plants. In this case, some studies with maize confirmed histopathological changes in the liver and the kidneys of rats after GM feed consumption. Such changes consist in congestion, cell nucleus border changes, and severe granular degeneration in the liver
[16]. Similarly, in the MON810 studies, a significantly lower albumin/globulin ratio indicated a change in hepatic metabolism of $33 \%$ of GM-fed male rats (according to EFSA opinion on MON810 and [5]). Taken together, the results indicate potential adverse effects in hepatic metabolism. The insecticide produced by MON810 could also induce liver reactions, like many other pesticides. Of course, the mCry1Ab and other $\mathrm{mBt}$ (mutated Bt toxins derived from native Bacillus thuringiensis toxins) in GMOs are proteic toxins; however, these are modified at the level of their amino acid sequence by biotechnologies and introduced by artificial vectors, thus these could be considered as xenobiotics (i.e., a molecule foreign to life). The liver together with the kidneys are the major reactive organs in case of food chronic intoxication.

\section{Kidney parameters}

In the NK603 study, statistically significant strong urine ionic disturbances and kidney markers could be explained by renal leakage [5], which is well correlated with the effects of glyphosate-based herbicides (like Roundup) observed on embryonic kidney cells [23]. This does not exclude metabolic effects indirectly due to insertional mutagenesis linked to the plant transformation. Roundup adjuvants even stabilize glyphosate and allow its penetration into cells, which in turn inhibit estrogen synthesis as a side effect, cytochrome P450 aromatase inhibition [21]. This phenomenon changes the androgen/estrogen ratio and may at least, in part, explain differential impacts in both sexes.

Kidney dysfunctions are observed with $\mathrm{mBt}$ maize producing mutated insecticides such as in MON863. For instance, we quote the initial EFSA report: "Individual kidney weights of male rats fed with the 33\% MON863 diet were statistically significantly lower compared to those of animals on control diets", "small increases in the incidences of focal inflammation and tubular regenerative changes in the kidneys of 33\% MON863 males." This was confirmed by the company tests [25] and another counter analysis revealed disrupted biochemical

Table 2 Meta-analysis of statistical differences with appropriate controls in feeding trials

\begin{tabular}{|c|c|c|c|c|}
\hline \multirow[t]{2}{*}{ All parameters measured in vivo in GMO toxicity studies } & \multicolumn{2}{|c|}{$\begin{array}{l}\text { Measured by organ } \\
(\%) / \text { Total }(694-698)\end{array}$} & \multicolumn{2}{|c|}{$\begin{array}{c}\text { Disturbed in each organ (\%)/Total disrupted } \\
\text { parameters (approximately } 9 \% \text { ) }\end{array}$} \\
\hline & Females & Males & Females & Males \\
\hline Liver & 22.9 & 22.9 & 30.8 & 26.1 \\
\hline Kidney & 23.7 & 23.7 & 26.4 & 43.5 \\
\hline Bone marrow & 29.5 & 29.5 & 29.7 & 22.8 \\
\hline Total for 3 tissues & 76.1 & 76.1 & 86.9 & 92.4 \\
\hline
\end{tabular}

Commercialized soybean and maize GMOs were fed to rats and their blood analyses were obtained. The different parameters are classified according to the tissue [2] to which they are related (e.g., liver, kidney, bone marrow). Of the total parameters measured $76.1 \%$ are related to these three organs. The percentages of significantly different parameters to the controls are called "disrupted parameters." There are in total $9 \%$ of disrupted parameters and, for instance, $43.5 \%$ of these are concentrated in kidneys in males. The bold values are significantly over the parameters measured per organ. 
markers typical of kidney filtration or function problems [2]. The first effects were not always but sometimes greater than the ones with non-isogenic maize (called reference lines), which contain different salts, lipids, or sugars. Moreover, both results described are different between males and females; this is quite usual in liver or kidney pesticide reactions. These facts do not exclude that such effects can be considered as treatment-related. Other studies also confirmed effects on kidneys. Tubular degeneration and not statistically significant enlargement in parietal layer of Bowman's capsules were also observed with GM maize fed rats [16].

Last but not least, a total of around $9 \%$ of parameters were disrupted in a meta-analysis (Table 2). This is twice as much as what could be obtained by chance only (generally considered as 5\%). Surprisingly, $43.5 \%$ of significant different parameters were concentrated in male kidneys for all commercialized GMOs, even if only around $25 \%$ of the total parameters measured were kidney-related. If the differences had been distributed by chance in the organs, not significantly more than $25 \%$ differences would have been found in the kidney. Even if our own counter analysis is removed from the calculation, showing numerous kidney dysfunctions [2], around $32 \%$ of disturbances are still noticed in kidneys.

\section{Discussion}

\section{Need for chronic tests and other tests}

Chronic toxicity tests (both with males and females) and reproductive tests with pregnant females and then with the developing progeny over several generations (none of these steps exist at present) are called as a whole the Toxotest approach (or Risk management test, see "Details on the new suggested Toxotest approach"). This could address the long-term physiological or pathological relevance of the previous observations. The physiological interpretations of 90-day-based effects are otherwise somewhat limited. These studies should be complementary to the present regulations or the Safotest and the sentinel test suggested by EFSA [1]. The Toxotest could provide evidence of carcinogenic, developmental, hormonal, neural, and reproductive potential dysfunctions, as it does for pesticides or drugs. Additionally, it is obvious that the 90-day-long trials on mature animals performed today cannot scientifically replace the sensitivity of developmental tests on neonates. A good example is the gene imprinting by drugs that will be revealed only at maturity; this is an important subject of current research, and many findings have been reported for some chemicals such as bisphenol A $[26,27]$. Even transgenerational effects occur after epigenetic imprinting by a pesticide [28]. These effects cannot be detected by classical 90 -day feeding trials and will be visible after many decades by epidemiology in humans if any, as illustrated in the case of diethylstilbestrol, which induced female genital cancers among other problems in the second generation [29]. The F3 multigenerational study for a GMO (Table 1) was too rarely performed. This is why, because of the number of parameters disrupted in adult mammals within 90 days, the new experiments should be systematically performed to protect the health of billions of people that could consume directly or indirectly these transformed products.

The acute toxicity approach (less than a month of investigations on rodents with high doses) may give effects which are more proportional to the dose, as it might correspond to a rapid poisoning of the animals, generally with force-fed experiments. However, for many pesticide studies in the scientific literature, some long-term side effects of pesticides at environmental doses are described, which are not apparent in shortterm experiments [30]. Classical toxicology is quite often based on the concept of revealing linear doseresponses as defined by Paracelsus, which generally fails to evidence $U$ or J curves observed after hormonal sexspecific disruptions. Moreover, the effects of mixtures are also neglected in long-term studies, when supposed active principles of pesticides are not assessed with their adjuvants, which also are present as residues in GMOs. Such pesticides may have the capacity to disrupt the "cell web", i.e., to interfere with a signaling pathway, and this could be unspecific. For instance Roundup is known to disrupt the EPSPS in plants, but is also known to interact with the mammalian ubiquist reductase [21] common and essential to cytochromes P450, a wide class of detoxification enzymes. The so-called Roundup active principle, glyphosate, acts in combination with adjuvants to increase glyphosate-mediated toxicity $[21,31]$, and this may apply to other environmental pollutants [22]. Moreover, all new metabolites in edible Roundup ready GMOs, as acetyl-glyphosate for the new GAT GMOs, have not been assessed for their chronic toxicity [11], and we consider this as a major oversight in the present regulations.

Therefore, as xenobiotic effects are complex, the determination of their toxic effects cannot be determined using a single method, but rather converging pieces of evidence. In GMO risk assessment, the protocols must be optimized to detect side effects, in particular for herbicide-treated GM plants. These cannot be reduced to GM assessment on one side and herbicide residues with any diet on the other side, but unfortunately this has been the case, and this approach has been promoted up to now by regulatory authorities.

In fact, it is impossible, within only 13 weeks, to conclude about the kind of pathology that could be induced by pesticide GMOs and whether it is a major pathology or a minor one. It is therefore necessary to prolong the 
tests, as suggested by EFSA, since at least one third of chronic effects visible with chemicals are usually new in comparison to the ones highlighted in subchronic studies [1]. The so-called Toxotests, which are supposed to include the studies of chronic pathologies in particular, should be performed on three mammalian species, with at least one non-rodent, similar to the type of rodents used for pesticides and drugs. However, the chronic feeding tests for GMOs cannot be based on the no observed adverse effect level, nor on the lowest observed adverse effect level approach, as in classical toxicology. There are several reasons for that. There is not only one chemical, but also several unknown metabolites and components, in Roundup tolerant varieties for instance, and therefore toxicity is enhanced thanks to the fact that they are mixed together. There is also no possibility of increasing the doses of GMOs in an equilibrated diet over an acceptable level. The diets should be rather representative of an equilibrated diet with GMOs like it could be the case in a real population in America. To prolong 90-day subchronic tests with three normal doses of GM in the diet (11\%, 22\%, 33\% for instance) is the solution.

\section{Sex- or dose-specific pathological effects are common}

When there is a low or environmental dose impregnation of the feed (with a pesticide GM plant for instance), the chronic effects could be more differentiated according to the sex, the physiological status, the age, or the number of intakes over such and such a period of time in the case of a drug. These parameters (chronic intake, age of exposure, etc.) are more decisive for pathologies like cancers, than the actual quantity of toxin ingested in one intake. This is in part because the liver, kidney, and other cytochrome P450-rich organs are concerned for long-term metabolism and detoxification, and this phenomenon is hormone dependent. It is also due to the process of carcinogenesis or hormone-sensitive programming of cells [32]. The liver for instance is a sex differentiated organ as far as its enzymatic equipment is concerned [4]. An effect in subchronic or chronic tests cannot be disregarded on the rationale that it is not linear to the dose (or dose-related) or not comparable in genders. This would not be scientifically acceptable. However, this reasoning was adopted both by companies and EFSA for several GMOs, as underlined by Doull et al. [33]. Indeed, most xenobiotics or pollutants may have non-linear effects, and/or may have sex- and agespecific impacts.

One of the pivotal requirements for regulators nowadays, in order to interpret a significant difference as biologically relevant, is to observe a linear dose-response. This allows them to deduce a causality. However, this dose-response cannot be studied with only two points, which is nonetheless the case for all major commercial GMOs today, which are given in the diet in $11 \%$ and $33 \%$ concentrations only, in subchronic tests. This is true overall if no preliminary data has been obtained to choose the given doses, which is the case in regulatory files. As we have already emphasized, most of pathological and endocrine effects in environmental health are not directly proportional to the dose, and they have a differential threshold of sensitivity in both sexes [34]. This is, for instance, the case with carcinogenesis and endocrine disruption.

\section{Improving the knowledge on impacts of modified Bt toxins}

One of the interpretations of the side effects observed (Tables 1 and 2) would be that the insecticide toxins in maize lines may have more pleiotropic or specific actions than originally supposed. The toxins could generate particular metabolites, either in the GM plant or in the animals fed with it. The Bt toxins in GMOs are new and modified, truncated, or chimerical in order to change their activities/ solubility in comparison to wild Bt. For instance, there is at least a $40 \%$ difference between the toxin in Bt176 and its wild counterpart [10]. None of the modified Bt toxins have been authorized separately for food or feed, neither has the wild Bt, and neither have they been tested by themselves on animal or human health to date. Even if some studies were performed, the receptors have not been cloned and the signaling pathways have not been identified as yet, nor required for authorizations, and the metabolism of these proteins in mammals are unknown [35]. Thus, the argument about "safe use history" of the wild Bt protein (not designed for direct consumption, in contrast to several GMOs) cannot, on a sound scientific basis, be used for direct authorizations of the above-cited GM corns, overall without in vivo chronic toxicity tests (or Toxotest approach), as it is requested for a pesticide. Some improvements may even be included with regard to pesticide legislation, since these human modified toxins considered as xenobiotics are continuously produced by the plants devoted to consumption.

The proteins usually compared (modified Bt toxins and wild ones) are not identical, and the tests on human cells of Bt proteins are not performed nor are they requested by authorities. Their stability has been assessed in vitro, and GM insecticide toxins are never fully digested in vivo [36]. If some consumers suffer from stomach problems or ulcers, the new toxins will possibly act differently; the digestion in children could be affected too; however, these GMOs could be eaten anywhere and all proteins are never fully decomposed in amino acids by the digestive tract. 


\section{Details on the new suggested Toxotest approach}

The suggested Toxotest would basically include an extension of the existing 90-day tests, but with at least three doses plus controls $(0 \%, 11 \%, 22 \%, 33 \%$ GMOs for instance; today the equilibrated diets tested contain $0 \%$, $11 \%$, and $33 \%$ GMOs in the best regulatory tests). The purpose would be to characterize scientifically the doseresponse approach. The latter cannot be taken seriously with only two GM doses. The final goal is the best health protection for the population without really possible clinical trials, in our case for practical and ethical reasons. There is also no epidemiological follow-up for lack of traceability and labeling in GM-producing American countries. In addition, the fact that the Toxotest includes the best possible toxicological approach will also be in favor of the biotechnology economy and the European Community because it is more expensive to address an issue concerning a whole population afterwards, rather than to work with laboratory animals beforehand; it is also more ethical to work on rats and other mammalian experiments, in order to get the relevant information, rather than to give pesticide plants directly to humans on a long-term basis.

As previously underlined, the health effects such as those suggested in Table 2 (if any, are revealed by adapted studies, such as Safotests or Toxotests), could only be due to two possibilities:

Firstly, the side effects may be directly or indirectly due to a pesticide residue and/or its metabolites. The direct effect is about the pesticide effect on the consumer, and the indirect one is about a metabolism disruption that it has provoked within the plant first. This could not be visible by a detailed compositional analysis, such as the one performed to be assessed by a substantial equivalence study. This concept is not a well-defined one (how many cultivations of crops, over how many years, under which climate, and to measure what precise parameters).

Secondly, the pathological signs may be due to the genetic transformation itself, its method provoking either insertional mutagenesis or a new metabolism by genetic interference. This is the reason why separating intended effects (the direct genetic trait consequence itself) from unintended effects (linked to biotechnology, e.g., insertional mutagenesis), such as spiking the control diet with the purified toxin in the Toxotest approach, is clearly inadequate. It could work in the case of a direct action of the toxin in mammals, but conversely one could not conclude, between an insertional mutagenesis and a specific metabolic action in the plant due to the toxin. However, this is more a research question about the mode of genesis of an effect on health, and new research avenues could be, for instance, to compare the GM diet with or without herbicide treatment in long- term tests with the isogenic control diet including herbicide residues added. This is only necessary for the understanding of the potential signs of toxicity and not for a conclusion of the Safotest or the Toxotest, which would rather suggest, if positive, excluding immediately the corresponding GMO from food and feed.

\section{Improvement of statistical analysis}

A serious experimental design is based on a proper choice of the groups, with only one question studied per experiment if possible, and balanced sample sizes. In several authorized GMOs, the sample sizes appear inadequate in 90 days: ten animals per group for the measurement of biochemical parameters out of 20, as performed by the major stakeholders, and accepted by EFSA for MON863, MON810, or NK603 for instance. This is too limited a size to ensure that parametric statistical methods used by the company are reliable. Moreover, an important discrepancy between GMOtreated rats (40 measured out of 80 ) and the total number of animals (400) renders more difficult the evidencing of relevant effects, and confusion factors are brought in at the same time with six different reference diets in addition to the two normal control groups as performed in three commercialized GMOs at least $[5,6]$. This introduces new uncontrolled sources of variability about the effects of the diets and new unnecessary questions not relevant to the GMO safety. The representation of a standard diet with multiple sources could have been studied with only one control group of the same size than the GMO group, eating a mix of six different regular non-GM diets.

Several questions have been raised by companies and authorities as well as comments on statistically significant effects that would supposedly not be biologically meaningful. A subjective part is introduced at this level because it is necessary to take into account the context and the general and detailed knowledge of toxicology and endocrine disruption, as EFSA underlines. This might be highly expert dependent. This is why, to avoid or prevent any misunderstanding, we suggest, in addition to a new statistical approach based on classical methods, to analyze the 90-day tests, even with control and reference diets called the "SSC method" (according to the initials of the authors in [2]).

Briefly, following the necessity to model and analyze the growth curves, multivariate data analysis and data mining of all parameters can be used to correlate, cluster, and select meaningful variables. This kind of approach is not performed at all today. Thereafter, the detailed comparison between GM-treated and control groups, fed with the near isogenic line (because the real isogenic line does not often exists anymore), will necessarily be followed by the study of specific diet effects, 
when there are non-substantially equivalent diets for reference groups. For that purpose, the controls will be first compared using multivariate inference with reference groups, and thereafter, similarly GMO-treated groups with reference groups. The significant differences linked to the GMO and/or the composition of the diet will be classified according to organ and function. The results will appear more clearly than with the simple statistics accepted today by the authorities (that is, comparison of the highest GM dose group with the mean value of all six control groups), and will reveal in addition new information, as it can be demonstrated.

As recommended by EFSA, an appropriate and relevant statistical analysis is crucial. It should follow the following series of steps, allowing the use of several methods depending on the questions raised:

- Obtaining and modeling the growth curves and feed consumption, assessed by non-linear regression, validation, and statistical comparisons in order to test if the curves are significantly different, thus taking into account individual variability. This necessitates the use of time series analysis, selection models, and nonparametric tests, Akaike Information Criteria and related methods. Water consumption should also be an important factor to follow-up and therefore better understand kidney and urine data.

- The study of dose-response predictions using nonlinear regression should be the goal, but the only two doses generally used in these tests do not make it possible to evidence linearity as we indicated. Moreover, in the cases where there are not doserelated trends or relationships using the two doses mentioned, the absence of linear dose-response curves cannot be a reason to neglect the effects. For instance, as previously cited, $U$ or J curves may be characteristic of endocrine effects [37], and spiky irregular curves may be detected in carcinogenesis.

- Simultaneous analysis of all observed variables: multivariate data analysis, principal component analysis, correlations analysis, factorial analysis and clustering

- Multivariate comparisons of the different variables: hypothesis testing, multiple ways ANOVA, MANOVA, and others to determinate if the groups differ relative to the different questions: specific GMO effect or diet effect per se. To evidence a detail, when comparing two mean values, SEM should be calculated to determine confidence intervals; however, SD have been used up to now by the company for MON863 and NK603 files for instance.

Apart from empirical curves in some instances, ANOVA and univariate hypothesis testing only the
GMO effect, none of the other statistical approaches is currently used nor requested by the authorities.

\section{Human tests and post-market monitoring}

For the record, it must be said that very few tests on humans have been carried out up to now. Moreover, epidemiological studies are not feasible in America, since there is no organized traceability of GMOs anywhere on the continent, where, by far, most of edible GMOs are cultivated (97\%). As a consequence, a postmarket monitoring (PMM) is offered to the population. The Cartagena Biosafety Protocol identifying GMOs at the borders of a country has now been signed by over 150 countries, including the member states of the European Union. PMM may have some value in detecting unexpected adverse effects. It could therefore be considered as a routine need. This approach makes it possible to collect information related to risk management. It can be relied upon as a technique for monitoring adverse events or other health outcomes related to the consumption of GM plant-derived foods, provided that the Toxotest approach, together with the SSC method, should have already been applied. The PMM should be linked with the possibility of detecting allergenicity reactions to GMOs in routine medicine, thanks to the very same routine cutaneous tests that should be developed prior to large-scale commercialization. A screening of serum banks of patients with allergies could be also put forward in order to search for antibodies against the main GMOs and not only their transgenic proteins, since they may induce secondary allergenic metabolites in the plant not visible in the substantial equivalence study.

The traceability of products from animals fed on GMOs is also crucial. The reason for this is because they can develop chronic diseases which are not utterly known today. Such possible diseases could be linked to the hepatorenal toxicity observed in some GMO-related cases (Table 1).

Moreover, labeling animals fed on GMOs is therefore necessary because some pesticide residues linked to GMOs could pass into the food chain and also because nobody would want to eat disabled or physiologically modified animals after long-term GMOs ingestion, even if pesticides residues or DNA fragments are not toxic nor transmitted by themselves.

\section{Conclusion}

Transcriptomics, proteomics and other related methods are not ready yet for routine use in the laboratories, and moreover they may be inappropriate for studying toxicity in animals, and could not in any way replace in vivo studies with all the physiological and biochemical parameters that are measured with organs weight, 
appearance, and histology. By contrast, afterwards, new approaches could well help to explain pathological results or action mechanisms of pesticides present in the GM plants or GM-fed animals, if found.

To obtain the transparency of raw data (including rat blood analyses) for toxicological tests, maintained illegally confidential, is crucial. It has also become crucial to apply objective criteria of interpretation like the criteria described here: sex-specific side effects or non-linear ones. Such data can be put online on the EFSA website with a view to provide a fuller review to the wider scientific community, and in order to better inform the citizen to make biotechnologies more socially acceptable. Since fundamental research is published on a regular basis, it should be the same for this kind of applied research on long-term health effects, as suggested by the CE/2001/18 and the corresponding 1829/2003 regulations.

We can conclude, from the regulatory tests performed today, that it is unacceptable to submit 500 million Europeans and several billions of consumers worldwide to the new pesticide GM-derived foods or feed, this being done without more controls (if any) than the only 3 -month-long toxicological tests and using only one mammalian species, especially since there is growing evidence of concern (Tables 1 and 2). This is why we propose to improve the protocol of the 90-day studies to 2-year studies with mature rats, using the Toxotest approach, which should be rendered obligatory, and including sexual hormones assessment too. The reproductive, developmental, and transgenerational studies should also be performed. The new SSC statistical method of analysis is proposed in addition. This should not be optional if the plant is designed to contain a pesticide (as it is the case for more than $99 \%$ of cultivated commercialized GMOs), whilst for others, depending on the inserted trait, a case-by-case approach in the method to study toxicity will be necessary.

\section{Acknowledgements}

We thank the CRIIGEN scientific committee for helpful discussions and structural support, as well as the Risk Pole (MRSH-CNRS, University of Caen, France). We acknowledge the French Ministry of Research for financial support and the Regional Council of Basse-Normandie. We are grateful to Herrade Hemmerdinger for the English revision of this manuscript.

\section{Author details}

'Laboratory of Biochemistry - IBFA, University of Caen, Esplanade de la Paix, 14032 Caen, Cedex, France ${ }^{2}$ CRIIGEN, Paris, France ${ }^{3}$ University of Rouen LITIS EA 4108, 76821 Mont-Saint-Aignan, France

\section{Authors' contributions}

GES designed and coordinated the review. RM participated in the drafting of the manuscript and final version. EC, SG, JSV and DC helped the writing, compiling the literature, revising in details and proofreading the manuscript. All authors read and approved the final manuscript.

\section{Competing interests}

The authors declare that they have no competing interests.
Received: 17 January 2011 Accepted: 1 March 2011

Published: 1 March 2011

\section{References}

1. EFSA: Safety and nutritional assessment of GM plants and derived food and feed: the role of animal feeding trials. Food Chem Toxicol 2008, 46: S2-70.

2. Séralini GE, Cellier D, Spiroux J: New analysis of a rat feeding study with a genetically modified maize reveals signs of hepatorenal toxicity. Arch Environ Contam Toxicol 2007, 52:596-602.

3. Séralini G-E: Comment on Transgenic aubergines put on ice. Naturenews 2009

4. Séralini GE, Spiroux J, Cellier D, Sultan C, Buiatti M, Gallagher L, Antoniou M, Dronamraju KR: How subchronic and chronic health effects can be neglected for GMOs, pesticides or chemicals. Int J Biol Sci 2009, 5:438-443.

5. Spiroux J, Roullier F, Cellier D, Séralini GE: A comparison of the effects of three GM corn varieties on mammalian health. Int J Biol Sci 2009, 5:706-726.

6. Spiroux J, Cellier D, Vélot C, Clair E, Mesnage R, Séralini GE: Debate on GMOs health risks after statistical findings in regulatory tests. Int J Biol Sci 2010, 6:590-598.

7. James C: Global Status of Commercialized Biotech/GM Crops. ISAAA Brief 412009.

8. Vom Saal FS, Hughes $C$ : An extensive new literature concerning low-dose effects of bisphenol A shows the need for a new risk assessment. Environ Health Perspect 2005, 113:926-933.

9. Myers JP, vom Saal FS, Akingbemi BT, Arizono K, Belcher S, Colborn T, Chahoud I, Crain DA, Farabollini F, Guillette LJ Jr, Hassold T, Ho SM, Hunt PA, Iguchi T, Jobling S, Kanno J, Laufer H, Marcus M, McLachlan JA, Nadal A, Oehlmann J, Olea N, Palanza P, Parmigiani S, Rubin BS, Schoenfelder G, Sonnenschein C, Soto AM, Talsness CE, Taylor JA, Vandenberg LN, Vandenbergh JG, Vogel S, Watson CS, Welshons WW, Zoeller RT: Why public health agencies cannot depend on good laboratory practices as a criterion for selecting data: the case of bisphenol A. Environ Health Perspect 2009, 117:309-315.

10. Séralini G-E: Ces OGM qui changent le monde France: Flammarion; 2004

11. EFSA: Modification of the residue definition of glyphosate in genetically modified maize grain and soybeans, and in products of animal origin on request from the European Commission. EFSA Journal 2009, 7:42.

12. Rosati A, Bogani P, Santarlasci A, Buiatti M: Characterisation of $3^{\prime}$ transgene insertion site and derived mRNAs in MON810 YieldGard maize. Plant Mol Biol 2008, 67:271-81.

13. Manetti C, Bianchetti C, Casciani L, Castro C, Di Cocco ME, Miccheli A, Motto M, Conti F: A metabonomic study of transgenic maize (Zea mays) seeds revealed variations in osmolytes and branched amino acids. J Exp Bot 2006, 57:2613-2625

14. Zhu Y, Li D, Wang F, Yin J, Jin H: Nutritional assessment and fate of DNA of soybean meal from roundup ready or conventional soybeans using rats. Arch Anim Nutr 2004, 58:295-310.

15. Vecchio L, Cisterna B, Malatesta M, Martin TE, Biggiogera M: Ultrastructural analysis of testes from mice fed on genetically modified soybean. Eur J Histochem 2004, 48:448-454.

16. Kilic A, Akay MT: A three generation study with genetically modified Bt corn in rats: biochemical and histopathological investigation. Food Chem Toxicol 2008, 46:1164-1170.

17. Malatesta M, Caporaloni C, Gavaudan S, Rocchi MB, Serafini S, Tiberi C, Gazzanelli G: Ultrastructural morphometrical and immunocytochemical analyses of hepatocyte nuclei from mice fed on genetically modified soybean. Cell Struct Funct 2002, 27:173-180.

18. Malatesta M, Perdoni F, Santin G, Battistelli S, Muller S, Biggiogera M: Hepatoma tissue culture (HTC) cells as a model for investigating the effects of low concentrations of herbicide on cell structure and function. Toxicol In Vitro 2008, 22:1853-1860.

19. Malatesta M, Tiberi C, Baldelli B, Battistelli S, Manuali E, Biggiogera M: Reversibility of hepatocyte nuclear modifications in mice fed on genetically modified soybean. Eur J Histochem 2005, 49:237-242.

20. Arregui MC, Lenardon A, Sanchez D, Maitre MI, Scotta R, Enrique S: Monitoring glyphosate residues in transgenic glyphosate-resistant soybean. Pest Manag Sci 2004, 60:163-166.

21. Richard S, Moslemi S, Sipahutar H, Benachour N, Séralini GE: Differential effects of glyphosate and roundup on human placental cells and aromatase. Environ Health Perspect 2005, 113:716-720. 
22. Benachour N, Sipahutar H, Moslemi S, Gasnier C, Travert C, Séralini GE: Time- and dose-dependent effects of roundup on human embryonic and placental cells. Arch Environ Contam Toxicol 2007, 53:126-133.

23. Benachour N, Séralini GE: Glyphosate formulations induce apoptosis and necrosis in human umbilical, embryonic, and placental cells. Chem Res Toxicol 2009, 22:97-105.

24. Gasnier C, Dumont C, Benachour N, Clair E, Chagnon MC, Séralini GE: Glyphosate-based herbicides are toxic and endocrine disruptors in human cell lines. Toxicology 2009, 262:184-191.

25. Hammond B, Lemen J, Dudek R, Ward D, Jiang C, Nemeth M, Burns J: Results of a 90-day safety assurance study with rats fed grain from corn rootworm-protected corn. Food Chem Toxicol 2006, 44:147-160.

26. Braniste $V$, Jouault $A$, Gaultier E, Polizzi A, Buisson-Brenac C, Leveque M, Martin PG, Theodorou V, Fioramonti J, Houdeau E: Impact of oral bisphenol $A$ at reference doses on intestinal barrier function and sex differences after perinatal exposure in rats. Proc Natl Acad Sci USA 2009, 107:448-453.

27. Braun JM, Yolton K, Dietrich KN, Hornung R, Ye X, Calafat AM, Lanphear BP: Prenatal bisphenol A exposure and early childhood behavior. Environ Health Perspect 2009, 117:1945-1952.

28. Anway MD, Cupp AS, Uzumcu M, Skinner MK: Epigenetic transgenerational actions of endocrine disruptors and male fertility. Science 2005, 308:1466-1469.

29. Wise LA, Palmer JR, Rowlings $K$, Kaufman RH, Herbst AL, Noller KL, TitusErnstoff L, Troisi R, Hatch EE, Robboy SJ: Risk of benign gynecologic tumors in relation to prenatal diethylstilbestrol exposure. Obstet Gynecol 2005, 105:167-173.

30. Hernandez AF, Casado I, Pena G, Gil F, Villanueva E, Pla A: Low level of exposure to pesticides leads to lung dysfunction in occupationally exposed subjects. Inhal Toxicol 2008, 20:839-849.

31. Benachour N, Moslemi S, Sipahutar H, Séralini GE: Cytotoxic effects and aromatase inhibition by xenobiotic endocrine disrupters alone and in combination. Toxicol Appl Pharmacol 2007, 222:129-140.

32. Melnick R, Lucier G, Wolfe M, Hall R, Stancel G, Prins G, Gallo M, Reuhl K, Ho SM, Brown T, Moore J, Leakey J, Haseman J, Kohn M: Summary of the National Toxicology Program's report of the endocrine disruptors lowdose peer review. Environ Health Perspect 2002, 110:427-431.

33. Doull J, Gaylor D, Greim HA, Lovell DP, Lynch B, Munro IC: Report of an Expert Panel on the reanalysis by of a 90-day study conducted by Monsanto in support of the safety of a genetically modified corn variety (MON 863). Food Chem Toxicol 2007, 45(11):2073-85.

34. Goldsmith JR, Kordysh E: Why dose-response relationships are often nonlinear and some consequences. J Expo Anal Environ Epidemiol 1993, 3:259-276.

35. Then C: Risk assessment of toxins derived from Bacillus thuringiensissynergism, efficacy, and selectivity. Environ Sci Pollut Res Int 2010, 17:791-797.

36. Paul V, Guertler P, Wiedemann S, Meyer HH: Degradation of Cry1Ab protein from genetically modified maize (MON810) in relation to total dietary feed proteins in dairy cow digestion. Transgenic Res 2010, 19(4):683-689.

37. Andrade AJ, Grande SW, Talsness CE, Grote K, Chahoud I: A dose-response study following in utero and lactational exposure to di-(2-ethylhexyl)phthalate (DEHP): non-monotonic dose-response and low dose effects on rat brain aromatase activity. Toxicology 2006, 227:185-192.

38. Malatesta M, Caporaloni C, Rossi L, Battistelli S, Rocchi MB, Tonucci F, Gazzanelli G: Ultrastructural analysis of pancreatic acinar cells from mice fed on genetically modified soybean. J Anat 2002, 201:409-415.

39. Malatesta M, Biggiogera M, Manuali E, Rocchi MB, Baldelli B, Gazzanelli G: Fine structural analyses of pancreatic acinar cell nuclei from mice fed on genetically modified soybean. Eur J Histochem 2003, 47:385-388.

40. Appenzeller LM, Munley SM, Hoban D, Sykes GP, Malley LA, Delaney B: Subchronic feeding study of herbicide-tolerant soybean DP-356043-5 in Sprague-Dawley rats. Food Chem Toxicol 2008, 46:2201-2213.

41. Sakamoto $Y$, Tada $Y$, Fukumori N, Tayama K, Ando H, Takahashi H, Kubo $Y$, Nagasawa A, Yano N, Yuzawa K, Ogata A: A 104-week feeding study of genetically modified soybeans in $\mathrm{f} 344$ rats. Shokuhin Eiseigaku Zasshi 2008, 49:272-282.

42. Appenzeller LM, Munley SM, Hoban D, Sykes GP, Malley LA, Delaney B: Subchronic feeding study of grain from herbicide-tolerant maize DP098140-6 in Sprague-Dawley rats. Food Chem Toxicol 2009, 47:2269-2280.
43. Hammond B, Dudek R, Lemen J, Nemeth M: Results of a 13 week safety assurance study with rats fed grain from glyphosate tolerant corn. Food Chem Toxicol 2004, 42:1003-1014.

44. Hammond BG, Dudek R, Lemen JK, Nemeth MA: Results of a 90-day safety assurance study with rats fed grain from corn borer-protected corn. Food Chem Toxicol 2006, 44:1092-1099.

45. MacKenzie SA, Lamb I, Schmidt J, Deege L, Morrisey MJ, Harper M, Layton RJ, Prochaska LM, Sanders C, Locke M, Mattsson JL, Fuentes A, Delaney B: Thirteen week feeding study with transgenic maize grain containing event DAS-01507-1 in Sprague-Dawley rats. Food Chem Toxicol 2007, 45:551-562.

46. He XY, Huang KL, Li X, Qin W, Delaney B, Luo YB: Comparison of grain from corn rootworm resistant transgenic DAS-59122-7 maize with nontransgenic maize grain in a 90-day feeding study in Sprague-Dawley rats. Food Chem Toxicol 2008, 46:1994-2002.

47. Malley LA, Everds NE, Reynolds J, Mann PC, Lamb I, Rood T, Schmidt J, Layton RJ, Prochaska LM, Hinds M, Locke M, Chui CF, Claussen F, Mattsson JL, Delaney B: Subchronic feeding study of DAS-59122-7 maize grain in Sprague-Dawley rats. Food Chem Toxicol 2007, 45:1277-1292.

48. Appenzeller LM, Malley L, Mackenzie SA, Hoban D, Delaney B: Subchronic feeding study with genetically modified stacked trait lepidopteran and coleopteran resistant (DAS-01507-1xDAS-59122-7) maize grain in Sprague-Dawley rats. Food Chem Toxicol 2009, 47:1512-1520.

doi:10.1186/2190-4715-23-10

Cite this article as: Séralini et al.: Genetically modified crops safety assessments: present limits and possible improvements. Environmental Sciences Europe 2011 23:10.

\section{Submit your manuscript to a SpringerOpen ${ }^{\mathcal{O}}$ journal and benefit from:}

- Convenient online submission

- Rigorous peer review

- Immediate publication on acceptance

- Open access: articles freely available online

- High visibility within the field

- Retaining the copyright to your article

Submit your next manuscript at springeropen.com 